IJLLS

10,2

138

Received 14 September 2020 Revised 23 November 2020 17 December 2020

4 January 2021

Accepted 5 January 2021

\section{Digital tools to support teacher professional development in lesson studies: a systematic literature review}

\author{
Stefan Hrastinski \\ Division of Digital Learning, KTH Royal Institute of Technology, Stockholm, Sweden
}

\begin{abstract}
Purpose - Lesson study is one of the most adopted models of teacher professional development. However, as education has become increasingly digital, this study aims to investigate the use of digital tools to support teacher professional development in lesson studies.

Design/methodology/approach - This article systematically reviews journal articles on the use of digital tools to support teacher professional development in lesson studies.

Findings - While the lesson study model is typically based on the premise that teachers prepare and observea lesson at a school, the reviewed research suggests that digital tools open new ways to conduct lesson studies. Six themes on the use of digital tools to support teacher professional development in lesson studies are identified: analyzing videos from the teachers' classrooms, analyzing external video resources, fictional animations as a complement to videos, structured digital lesson study work, hybrid teacher collaboration and digital teacher collaboration. Opportunities for further research are suggested.

Practical implications - The identified themes can inspire practice on how to use digital tools to support teacher professional development in lesson studies.

Originality/value - Little attention has been paid to the use of digital tools to support teacher professional development in lesson studies.
\end{abstract}

Keywords Lesson study, Digital tools, Teacher professional development

Paper type Literature review

\section{Introduction}

Lesson study is one of the most adopted models of teacher professional development, where a group of teachers jointly plan a lesson in detail and then observe and analyze the lesson (Fernandez, 2002; Lewis et al., 2006). It has been found to have a beneficial effect on the quality of teacher learning (Vermunt et al., 2019; Lewis et al., 2009) and pedagogical content knowledge (Coenders and Verhoef, 2019). Lesson studies are typically conducted live in the classroom by a teacher group at the school (Fernandez, 2002; Lewis et al., 2006). However, as digital tools have become more widely used in education, they have also become increasingly used as part of lesson studies. A digital tool is simply defined as software, digital media, websites or digital resources. For example, several studies have examined the use of digital tools in lesson studies in mathematics (e.g. Murooka, 2007; Pierce et al., 2011) and in foreign language education (e.g. Lander, 2015; Nami et al., 2016). Lesson studies have also been conducted completely online by using video conferencing as part of distance education programs (Holdhusen et al., 2008) or to connect different schools in real time (Isoda et al., 2017).

(C) Stefan Hrastinski. Published by Emerald Publishing Limited. This article is published under the Creative Commons Attribution (CC BY 4.0) licence. Anyone may reproduce, distribute, translate and create derivative works of this article (for both commercial and non-commercial purposes), subject to full attribution to the original publication and authors. The full terms of this licence may be seen at http:// creativecommons.org/licences/by/4.0/legalcode
International Journal for Lesson \& Learning Studies Vol. 10 No. 2, 2021 pp. $138-149$ Emerald Publishing Limited 2046-8253

DOI 10.1108/IJLLS-09-2020-0062 
There may be potential in using digital tools to reconsider how teacher professional development can be supported in lesson studies, an area that has been given relatively little attention in previous research. To provide an example, Soto et al. (2019) describe how instructors across the USA engaged in a lesson study by using digital tools to formulate goals, plan a common lesson, conduct research on students' learning and reflect on their teaching practice. Instructors used video conferencing for meetings, shared documents to reflect on and refine the lesson and shared slides to design the lesson plan. Through the use of digital tools, the instructors were enabled to collaborate on lesson studies, despite being geographically dispersed.

This article aims to investigate the use of digital tools to support teacher professional development in lesson studies. The aim is addressed by conducting a systematic literature review. The article begins with a theoretical background on teacher professional development, lesson study and the role of digital tools. Next, the systematic review's methodology is presented. Findings are described by identifying six themes. The article concludes with a discussion of its contributions, limitations and suggestions for further research.

\section{Research background}

In this section, teacher professional development, lesson study and the role of digital tools are discussed.

\section{Teacher professional development and digital tools}

Teacher professional development focuses on teacher learning, learning how to learn and how teacher knowledge can be put into practice to benefit student learning. It is described as "a complex process, which requires the cognitive and emotional involvement of teachers individually and collectively, the capacity and willingness to examine where each one stands in terms of convictions and beliefs, and the perusal and enactment of appropriate alternatives for improvement or change" (Avalos, 2011). Teacher professional development is generally perceived as being supportive and effective (Vescio et al., 2008; Turner et al., 2018), though one challenge is that many teacher groups entrench, rather than question, their assumptions and teaching practice (Timperley et al., 2008). Teacher groups need to have an intense focus on student learning (Vescio et al., 2008). Teacher professional development in groups can contribute to student-centered teaching and increased peer collaboration (Supovitz, 2002; Turner et al., 2018).

Fishman et al. (2013) conducted a randomized experiment to examine differences in teacher and student learning in face-to-face and online professional development. Significant gains were found for both teachers and students under both types of professional development. There were no significant differences between the face-to-face and online conditions. Kelly and Antonio (2016) studied teachers' peer support in open groups on Facebook. The teachers predominantly offered pragmatic advice and social support, but rarely reflected on or provided feedback about teaching practice. There is a significant body of research on video and video clubs for teacher professional development. A scoping review including 82 studies found that video seems effective when used as part of teacher professional development (Major and Watson, 2018). Such programs vary according to whether teachers watch videos of their own/their peers' instructions or unknown teachers and whether discussions are led by a facilitator or the teachers themselves. Video is increasingly used in teacher professional development, partly because video technology is more affordable and easy to use nowadays (Beisiegel et al., 2018).
Digital teacher professional development 
IJLLS
10,2

140

\section{Lesson study and digital tools}

Teachers who engaged in lesson study have been argued to gain an improved understanding of their students and to develop a student-centered approach through collaboration with peers (Cajkler et al., 2014; Lewis et al., 2009; Vermunt et al., 2019). The lesson study model is also suggested to contribute to teachers' knowledge and beliefs and the quality of teaching (Lewis et al., 2009). Positive effects have been identified in application-oriented learning, where teachers apply what they have learned to improve their teaching in the classroom, and meaning-oriented learning, where teachers want to know why things worked as they worked in the classroom. Meanwhile, negative effects have been identified in problematic learning, where teachers struggle with the education innovation. Less-experienced teachers had the highest gain in meaning-oriented learning (Vermunt et al., 2019; Bakkenes et al., 2010).

Lesson study groups formulate a research question or hypothesis, which is then pursued by planning for how to identify and gather evidence (Chokshi and Fernandez, 2004). Lesson studies are sometimes video recorded, which provides a detailed account of the lesson (Dudley, 2014) and supports teacher groups to review and reflect on their lesson (Fernandez, 2005). Video can be used in many different ways and is only one of many digital tools that teachers can use (Soto et al., 2019). As noted in the introduction, digital tools are already being used as part of research lessons, either implicitly because digital tools are commonly used nowadays in classrooms, or explicitly to better understand the role of a particular digital tool to support student learning (Murooka, 2007; Pierce et al., 2011; Lander, 2015; Nami et al., 2016). However, there is more limited research on how digital tools can be used to support teacher professional development in lesson studies. Therefore, this article reviews the use of digital tools to support teacher professional development in lesson studies.

\section{Methodology}

An integrative literature review critiques and synthesizes publications on a topic to provide new frameworks and perspectives (Cooper, 1998). This review will provide a better understanding of the use of digital tools to support teacher professional development in lesson studies. The integrative literature review includes five steps: problem formulation, collecting relevant studies, evaluating the studies, data analysis and presenting the findings (Cooper, 1998). The literature search for the review was conducted in October 2020. It is argued that a literature review should preferably be focused on a topic, rather than a sample of journals (Webster and Watson, 2002). A broad literature search was conducted, not limited to certain publication sources or years. The search was focused on journal articles because these are often of high quality because they are rigorously peer reviewed. The literature search was conducted in the Web of Science, Scopus and Eric (ProQuest) databases. The reasons for choosing these databases were that they have wide coverage of peer-reviewed journals while aiming to maintain quality. They also complement each other, because Web of Science and Scopus have a wider coverage, while Eric is focused on education.

A search string that combined the terms lesson study/studies with technical terms, i.e. computer, digital, e-learning, information and communication technology (ICT), online, social media, technology/technologies or video, was formulated. It was searched in titles, abstracts and keywords. The database search yielded a list of 206 articles, of which 102 articles were duplicates (Figure 1). Reasons for excluding publications were that (1) digital tools were used as part of a lesson, but not to support teacher professional development; (2) videos were used by researchers to collect empirical data but not as part of the lesson study; (3) a technical term was mentioned but was not the focus of the article; (4) the term lesson study was used in passing or with a different meaning; (5) the article was not in English; or (6) the article was not available in full text. In some cases, the abstracts did not provide enough detail, making it necessary to make the final decision based on the full text. Through this process, 12 articles 
were selected. Then, the reference lists of the selected articles were reviewed to identify articles that had not been found through the database searches. Forty-two potentially relevant journal articles were identified. Most of these articles examined video as part of teacher professional development but did not focus on lesson study. After reviewing the abstracts and full texts, only one article was deemed relevant. The reason that this article had not been found earlier was that it used the term on-line, rather than online.

The analysis of the publications was conducted as follows. First, the publications were read, and the aim and findings of each publication were noted in a spreadsheet. For example, the aim of a study written by Nickerson et al. (2014) was to "describe the lesson study context and share results of the investigation and affordances of [a] web site [to support and extend collaboration among teachers of mathematics at 26 school sites across two school districts]" (p. 152). The following is an example of a finding: "A significant percentage of the teachers used the web site for accessing resources, while a smaller fraction of teachers used the web site to discuss pedagogy and students' mathematical thinking” (p. 152).

The documentation in the spreadsheet was analyzed using thematic analysis, which is a method to identify, analyze and report themes in data (Braun and Clarke, 2006). The process of coding is an important part of thematic analysis (Miles and Huberman, 1994). First, initial codes were generated next to each publication. Examples of codes were "geographical dispersion," "peer review" and "video club." Then, the codes were collated into themes that were inductively identified. The publications were classified according to the themes in a recursive process, in which the themes were further refined. In the end, six themes were developed, which are presented in the next section.

\section{Findings}

Six themes on digital tools to support teacher professional development in lesson studies were identified: analyzing videos from the teachers' classrooms, analyzing external video resources, fictional animations as a complement to videos, structured digital lesson study work, hybrid teacher collaboration and digital teacher collaboration.

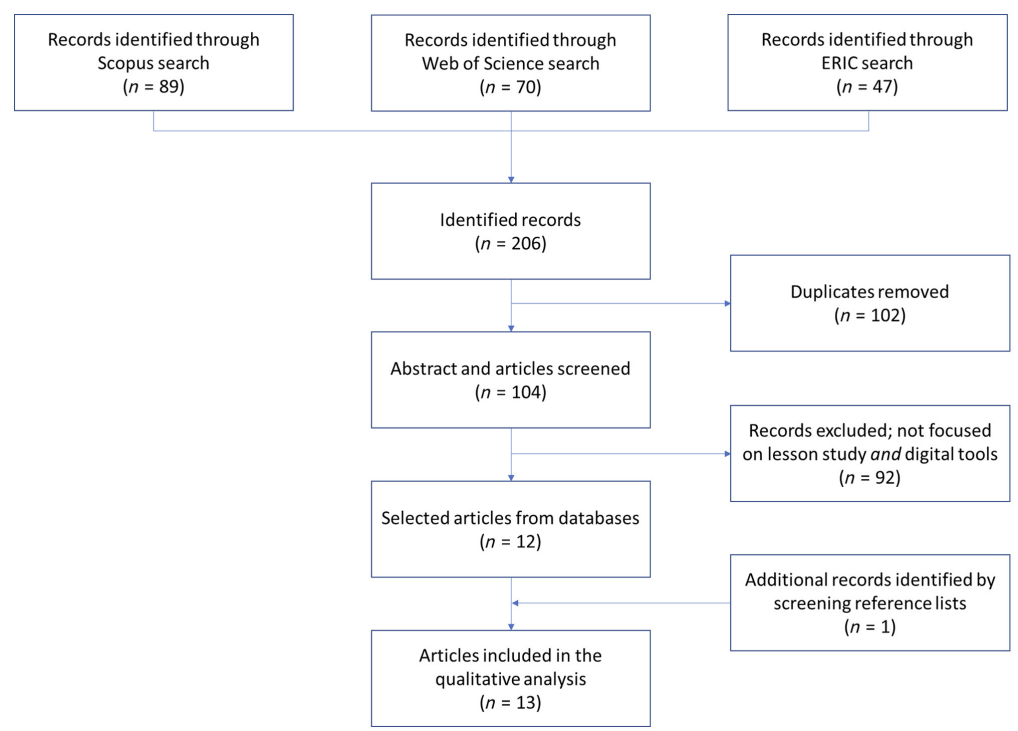

Figure 1. Article search and selection process

Digital teacher professional development 
IJLLS
10,2

142

Analyzing videos from the teachers' classrooms

The theme analyzing videos from the teachers' classrooms describes the use of teacher videos to encourage teacher learning in face-to-face lesson study meetings. Carrier (2011) described how video was used to record preservice teachers' lessons. The teachers were asked to view the lesson, discuss it with a partner and write a reflection. The preservice teachers started to identify their teaching style, in contrast, or in concert with their teaching partner, which can benefit their development as they become teachers.

Inoue (2011) described how consensus-building discussions in mathematics were implemented with a group of elementary teachers. In the meetings, the teachers were asked to bring a 15-20 min video segment of consensus-building discussions from their classrooms. Each teacher introduced the problem they had given to their students and then played the video. The lesson study group then discussed how the consensus building discussions could be better facilitated. The teachers learned to release control of class discussions and to support students to examine different strategies.

\section{Analyzing external video resources}

The theme analyzing external video resources describes the use of external videos to support teacher learning. Grant and Kline (2010) described video-based sessions that draw on many characteristics of lesson study, but video was used to scale up the lesson study model to include many teachers. In the study, videos of lessons were used to promote reflection among 189 elementary teachers when planning and implementing mathematics lessons. Many teachers believed their ability to question their students and probe their thinking was extended. The results suggested that video-based sessions could impact large numbers of teachers.

Fang et al. (2012) described how they developed video resources to support teacher discourse on improving student learning. A digital multimedia video case was developed based on research lessons on division with remainders conducted by teachers and researchers in Singapore. The video case described how teachers learned to use a model to improve student learning. Critical incidences were used to engage teachers in analyzing the research lessons. The videos were complemented by lesson study data, related readings and Web resources to support training and self-study. It was argued that video archives of research lessons could support teachers' continued learning.

\section{Fictional animations as a complement to videos}

The theme fictional animations as a complement to videos describes the use of fictional animated scenarios to support teachers' noticing of student thinking. González (2018) described a two-year professional development intervention with geometry teachers. The intervention combined discussions of animations of classroom instruction, videos and lesson study. The aim was to draw on students' prior knowledge to anticipate actions that promote mathematical understanding. It was hypothesized that representations of practice, such as animations or videos of classroom instructions, can support teachers' anticipation of actions by drawing on students' prior knowledge. The animations were stories of instruction portrayed by cartoons with a voiceover. In a related study, which also included fictional animations, it was found that teacher-initiated discussions of students' prior knowledge were more substantial than facilitator-initiated discussions. The findings suggested that the professional development model and the facilitators' moves promoted teachers' noticing of student thinking (González and Skultety, 2018).

Skultety et al. (2017) investigated whether the use of video and animations supported teachers' examination of student thinking and mathematical understanding in lesson study. Based on a study of four geometry teachers within a lesson study cycle, it was found that the 
teachers adapted the lesson based on their discussions of videos and animations. The study reported on a case where the videos and animations enabled the teachers to notice student thinking and elicit knowledge about students' mathematical understanding.

\section{Structured digital lesson study work}

The theme structured digital lesson study work describes the use of digital tools to guide teachers through the lesson study process in collaboration with peers. Wang et al. (2019) evaluated the use of an online lesson study platform, which was used by 24 primary school teachers. The platform guided teachers when preparing lesson plans, peer reviewing and discussing teaching videos, writing reflections and improving lesson studies. The platform was used in four phases: (1) preparing for and uploading lesson plans and teaching videos, (2) peer reviewing and discussing teaching videos in groups, (3) writing a teaching reflection journal that discussed approaches for improvement and (4) receiving recommendations of personalized learning resources by the platform. The platform also visualized to what extent the different teachers provided feedback to each other and categorized comments on the teacher's strengths and suggestions for improvement. It was suggested that the use of the platform fostered interaction among members and improved teachers' performance in learning process design.

\section{Hybrid teacher collaboration}

The theme hybrid teacher collaboration describes the use of digital tools to support teacher collaboration in addition to face-to-face lesson study meetings. Nickerson et al. (2014) described how they extended lesson study with a hybrid lesson study model. In addition to face-to-face lesson study meetings, they designed a website to support collaboration among mathematics teachers at 26 schools. The website provided access to lesson study documents, resources and articles, video segments of lessons with the possibility to discuss online in the lesson study team and more general discussions for all participants. Many teachers used the website to access resources, while a smaller number used it to discuss pedagogy and students' mathematical thinking. The hybrid lesson study model addressed time constraints of teachers and challenges of geographical distance when facilitating discussions among teachers from different schools.

\section{Digital teacher collaboration}

The theme digital teacher collaboration describes the use of digital tools to support collaboration among teachers that are not co-located. Koutsouris et al. (2017) examined the use of video conferencing and video sharing to support lesson study procedures to connect team members between schools and universities. Two lesson study teams conducted three research lessons. Each team consisted of two mathematics teachers, a mathematics lecturer and a psychologist. The teachers video recorded the lessons and uploaded them to a website. The university representatives watched the video in preparation for the next meeting. The meetings were held using video conferencing. Despite some technical difficulties, it was found that including university lecturers supported the teachers while reducing the practical constraint of bringing external professionals into lesson study teams.

Sharma and Pang (2015) explored pedagogical shifts of elementary teachers in an online lesson study on literacy tutoring. Three teams of teachers used shared documents to develop weekly lesson plans for the tutoring sessions. Each tutoring session was video recorded. The teachers were asked to share three 10 min video segments based on an "aha moment" or "something puzzling." The video segments were complemented with a written reflection. Then, video conferencing was used for weekly meetings. The identified pedagogical shifts 
IJLLS

10,2

144

were growth in knowledge of assessment, instructional differentiation skills and providing corrective instructions based on data-driven decisions.

Soto et al. (2019) described how participation in technology-facilitated lesson study enabled five geographically dispersed early-career higher education faculty across the USA to engage in professional development. They used video conferencing and shared documents to plan for a lesson study in mathematics for preservice elementary teachers. Each of them conducted the lesson, which was video recorded. Then, they reflected on their teaching practice. The authors argued that the technology-facilitated lesson study provided professional learning and note that they continue to hold weekly online meetings.

Stokes et al. (2020) compared teacher perceptions of social, emotional and instructional support during lesson study in-person as compared with via video. The study was based on 405 fifth- through ninth-grade teachers. The teachers felt social, emotional and instructional support, although the levels were higher during in-person lesson study. Notably, the levels of support did not differ between single-school-based or cross-school-based lesson study.

\section{Discussion}

This paper has reviewed the use of digital tools to support teacher professional development in lesson studies. Based on the reviewed studies, six themes were identified (Table 1).

\section{Analyzing videos from the teachers' classrooms}

This theme describes the use of teacher videos to support teacher learning in face-to-face lesson study meetings. Lesson studies are sometimes video recorded, and it has been acknowledged that videos can support lesson study teams to review and reflect on a lesson (Fernandez, 2005; Dudley, 2014). Moreover, many studies on video and video clubs for teacher professional development have been published (Major and Watson, 2018). There have been quite a few studies that have focused on how teachers analyze videos from their classrooms as part of lesson studies. In this review, it was found that analyzing videos from the teachers' classrooms can support their development as they become teachers and develop more student-centered teaching strategies (Carrier, 2011; Inoue, 2011). A future research

\begin{tabular}{|c|c|c|}
\hline Theme & Description & Benefit \\
\hline $\begin{array}{l}\text { Analyzing videos from } \\
\text { the teachers' classrooms }\end{array}$ & $\begin{array}{l}\text { Teacher videos are used to support } \\
\text { teacher learning in face-to-face lesson } \\
\text { study meetings }\end{array}$ & $\begin{array}{l}\text { Analyzing videos supports in-depth } \\
\text { review and reflection }\end{array}$ \\
\hline $\begin{array}{l}\text { Analyzing external } \\
\text { video resources }\end{array}$ & $\begin{array}{l}\text { External videos are used to support } \\
\text { teacher learning }\end{array}$ & $\begin{array}{l}\text { External videos can provide } \\
\text { perspectives that complement the } \\
\text { local lesson study }\end{array}$ \\
\hline $\begin{array}{l}\text { Fictional animations as a } \\
\text { complement to videos }\end{array}$ & $\begin{array}{l}\text { Fictional animated scenarios are used to } \\
\text { support teachers' noticing of student } \\
\text { thinking }\end{array}$ & $\begin{array}{l}\text { Fictional animated scenarios can be } \\
\text { designed with clear messages }\end{array}$ \\
\hline $\begin{array}{l}\text { Structured digital lesson } \\
\text { study work }\end{array}$ & $\begin{array}{l}\text { Teachers are guided by a digital tool } \\
\text { through the lesson study process in } \\
\text { collaboration with peers }\end{array}$ & $\begin{array}{l}\text { Teacher guidance through the } \\
\text { lesson study process can be partly } \\
\text { automated }\end{array}$ \\
\hline $\begin{array}{l}\text { Hybrid teacher } \\
\text { collaboration }\end{array}$ & $\begin{array}{l}\text { Digital tools are used to support teacher } \\
\text { collaboration in addition to face-to-face } \\
\text { meetings }\end{array}$ & $\begin{array}{l}\text { Teachers can access resources and } \\
\text { collaborate in addition to face-to-face } \\
\text { meetings }\end{array}$ \\
\hline $\begin{array}{l}\text { Digital teacher } \\
\text { collaboration }\end{array}$ & $\begin{array}{l}\text { Digital tools are used to support } \\
\text { collaboration among teachers that are not } \\
\text { co-located }\end{array}$ & $\begin{array}{l}\text { A team of teachers, who are not } \\
\text { co-located, can conduct a lesson } \\
\text { study together }\end{array}$ \\
\hline
\end{tabular}

Table 1.

Identified themes, descriptions and benefits
Teacher videos are used to support study meetings

External videos are used to support support teachers' noticing of student thinking Digital tools are used to support teacher Digital tools are used to support co-located
Analyzing videos supports in-depth

External videos can provide perspectives that complement the local lesson study

Fictional animated scenarios can be Teacher guidance through the lesson study process can be partly automated

Teachers can access resources and meetings

A team of teachers, who are not study together 
opportunity is to study how teachers are analyzing videos as part of lesson studies and how they can be supported in such analyses.

\section{Analyzing external video resources}

This theme describes the use of external video to support teacher learning. While the previous theme describes how teachers record videos of their teaching practice, external videos can provide input from other settings. External videos can be selected based on the focus of the lesson study team, which might support teacher preparation and reflection, with the potential to impact many teachers (Grant and Kline, 2010; Fang et al., 2012). In one study, videos were embedded as part of a website and complemented by lesson study data and resources to support teacher training (Fang et al., 2012). A future research opportunity is to examine how external videos can support teacher learning in lesson studies.

\section{Fictional animations as a complement to videos}

This theme describes the use of fictional animated scenarios to support teachers' noticing of student thinking. This theme has mainly been developed in a research group (González, 2018; González and Skultety, 2018; Skultety et al., 2017). While the two previous themes concern videos that are typically recordings of real classrooms, fictional animated scenarios can be designed with more clear messages. The focus has so far been on how to promote teachers' noticing of student thinking. A future research opportunity is to explore how other applications of fictional scenarios could be developed to promote teacher learning in lesson studies. Although the focus of this theme was animated scenarios, there might also be potential in developing fictional cases by using other media.

\section{Structured digital lesson work}

This theme describes the use of digital tools to guide teachers through the lesson study process in collaboration with peers. This means that the role of the facilitator is partly managed by the digital tool. It was described how teachers were guided through the lesson study process and were encouraged to provide feedback to peers and write teaching reflections (Wang et al., 2019). The digital tool also categorized the teacher's strengths and suggestions for improvement and suggested personalized learning resources. A future research opportunity is to study and develop digital tools that could guide and support teachers through the lesson study process.

\section{Hybrid teacher collaboration}

This theme describes how digital tools are used to support teacher collaboration in addition to face-to-face lesson study meetings. Nickerson et al. (2014) described how they designed a website to provide resources and support collaboration among teachers. Although many teachers used the website to access resources, a smaller number used it to discuss pedagogy and students' mathematical thinking. Similarly, Kelly and Antonio (2016) found that teachers predominantly offered pragmatic advice and social support, but rarely reflected on or provided feedback about teaching practice, in open Facebook groups. A future research opportunity is to better understand how digital collaboration could complement face-to-face teacher collaboration in lesson study teams.

\section{Digital teacher collaboration}

This theme describes how digital tools are used to support collaboration among teachers that are not co-located. The articles predominantly relied on video conferencing, but also used other digital tools, such as recorded videos and document sharing. The key benefit is that a
Digital teacher professional development 
IJLLS

10,2

146

team of teachers, who are not co-located, can conduct a lesson study together by, for example, using shared documents to develop lesson plans, recording videos from the classroom and using video conferencing to meet (Sharma and Pang, 2015; Soto et al., 2019). This approach has also been used to connect teachers with outside experts (Koutsouris et al., 2017). However, teachers engaged in digital collaboration might face challenges, such as feeling less social, emotional and instructional support, as compared with in-person lesson study (Stokes et al., 2020). That said, there are conflicting results in the research literature. For example, Fishman et al. (2013) conducted a randomized experiment to examine differences in teacher and student learning in face-to-face and online professional development, identifying no significant differences between face-to-face and online conditions. A future research opportunity is to better understand how to organize digital teacher collaboration in ways that are at least as effective as face-to-face lesson studies.

\section{Limitations}

Some limitations should be put forth. One challenge of systematic literature reviews is how to formulate a search string that identifies as many published articles that meet the inclusion criteria as possible. In this review, the terms lesson study and lesson studies were combined with technical terms. There might be additional technical terms that could have resulted in identifying more articles. However, to make sure that key articles were not omitted, the reference lists of the identified articles were scanned. In doing this, only one additional article was identified, indicating that most articles were identified through the database searches. Three databases, Web of Science, Scopus and Eric (ProQuest) were used. There might be other databases that could have been used, which might have provided additional articles. However, these are high-quality databases, indicating that most influential articles can be found in these databases. Perhaps the most important limitation is that related research topics, such as teacher reflection on video and video clubs (Major and Watson, 2018; Beisiegel et al., 2018), were not included in the review if they did not also explicitly focus on lesson studies. Future research could build on this review by examining how the use of digital tools to support lesson study could be informed by related research.

\section{Conclusions}

The aim of this article was to review the use of digital tools to support teacher professional development in lesson studies. The reviewed research suggests that digital tools open new ways to conduct lesson studies. In many respects, digital tools can be used as a complement without compromising the underlying premises of lesson studies. This is underlined by the fact that the use of video recordings is already widely recognized within (Fernandez, 2005; Dudley, 2014) and beyond lesson studies to support teacher professional development (Major and Watson, 2018; Beisiegel et al., 2018). It is also evident from the review that digital tools can be used to support teacher professional development in different ways by using other digital tools that complement the use of video recordings.

The identified themes can inspire further research and practice on the use of digital tools to support teacher professional development in lesson studies. Surprisingly, quite few journal articles were identified. Researchers are suggested to build on the themes and identify further opportunities. The review has implications for everyone involved in lesson study practices, including teachers, facilitators, team leaders and designers. The reviewed articles show that there are several ways that digital tools can be used to support teacher professional development in lesson studies. There is potential to complement local practices in classrooms and schools. For example, digital tools can support teachers when preparing and analyzing lesson studies, and recorded lesson studies from other settings can support professional 
development. Digital tools also open new ways to conduct lesson studies that would not otherwise be feasible. Teachers and facilitators, who would not have met face-to-face, can plan, conduct and reflect on lesson studies together. This has great potential to support lesson study professional development across schools and for those who might have few or no colleagues in their subject discipline at their local school.

During the Covid-19 pandemic, many teachers around the world had to quickly adopt digital tools to teach fully or partly online. Although this was a circumstance with little time for preparation, most teachers are now better prepared to use digital tools. When looking forward, this review can serve as a point of reference when planning to use digital tools to support teacher professional development in lesson studies, both within and beyond the local school.

\section{References}

Avalos, B. (2011), "Teacher professional development in teaching and teacher education over ten years", Teaching and Teacher Education, Vol. 27 No. 1, pp. 10-20.

Bakkenes, I., Vermunt, J.D. and Wubbels, T. (2010), "Teacher learning in the context of educational innovation: learning activities and learning outcomes of experienced teachers", Learning and Instruction, Vol. 20 No. 6, pp. 533-548.

Beisiegel, M., Mitchell, R. and Hill, H.C. (2018), "The design of video-based professional development: an exploratory experiment intended to identify effective features", Journal of Teacher Education, Vol. 69 No. 1, pp. 69-89.

Braun, V. and Clarke, V. (2006), "Using thematic analysis in psychology", Qualitative Research in Psychology, Vol. 3 No. 2, pp. 77-101.

Cajkler, W., Wood, P., Norton, J. and Pedder, D. (2014), "Lesson study as a vehicle for collaborative teacher learning in a secondary school", Professional Development in Education, Vol. 40 No. 4, pp. 511-529.

Carrier, S.J. (2011), "Implementing and integrating effective teaching strategies including features of lesson study in an elementary science methods course", The Teacher Educator, Vol. 46 No. 2, pp. $145-160$.

Chokshi, S. and Fernandez, C. (2004), "Challenges to importing Japanese lesson study: concerns, misconceptions, and nuances", Phi Delta Kappan, Vol. 85 No. 7, pp. 520-525.

Coenders, F. and Verhoef, N. (2019), "Lesson study: professional development (PD) for beginning and experienced teachers", Professional Development in Education, Vol. 45 No. 2, pp. 217-230.

Cooper, H.M. (1998), Synthesizing Research: A Guide for Literature Reviews, Sage, Thousand Oaks.

Dudley, P. (2014), Lesson Study: A Handbook, Lesson Study UK, Cambridge.

Fang, Y., Lee, C.K. and Yang, Y. (2012), "Developing curriculum and pedagogical resources for teacher learning", International Journal for Lesson and Learning Studies, Vol. 1 No. 1, pp. 65-84.

Fernandez, C. (2002), "Learning from Japanese approaches to professional development: the case of lesson study", Journal of Teacher Education, Vol. 53 No. 5, pp. 393-405.

Fernandez, M.L. (2005), "Learning through microteaching lesson study in teacher preparation", Action in Teacher Education, Vol. 26 No. 4, pp. 37-47.

Fishman, B., Konstantopoulos, S., Kubitskey, B.W., Vath, R., Park, G., Johnson, H. and Edelson, D.C. (2013), "Comparing the impact of online and face-to-face professional development in the context of curriculum implementation", Journal of Teacher Education, Vol. 64 No. 5, pp. 426-438.

González, G. (2018), "Understanding teacher noticing of students' prior knowledge: challenges and possibilities", Mathematics Enthusiast, Vol. 15 No. 3, pp. 483-528.

González, G. and Skultety, L. (2018), "Teacher learning in a combined professional development intervention", Teaching and Teacher Education, Vol. 71, pp. 341-354.
Digital teacher professional development 
IJLLS 10,2
Grant, T.J. and Kline, K. (2010), "The impact of video-based lesson analysis on teachers' thinking and practice", Teacher Development, Vol. 14 No. 1, pp. 69-83.

Holdhusen, M., James-Byrnes, C. and Rodriguez, L. (2008), "Lesson study for a distance education Statics course", ASEE Annual Conference and Exposition, Pittsburgh.

Inoue, N. (2011), "Zen and the art of neriage: facilitating consensus building in mathematics inquiry lessons through lesson study", Journal of Mathematics Teacher Education, Vol. 14 No. 1, pp. 5-23.

Isoda, M., Araya, R., Eddy, C., Matney, G., Williams, J., Calfucura, P., Aguirre, C., Becerra, P., Gormaz, R., Soto-Andrade, J., Noine, T., Mena-Lorca, A., Olfos, R., Baldin, Y. and Malaspina, U. (2017), "Teaching energy efficiency: a cross-border public class and lesson study in STEM", Interaction Design and Architecture(s), No. 35, pp. 7-31.

Kelly, N. and Antonio, A. (2016), "Teacher peer support in social network sites", Teaching and Teacher Education, Vol. 56, pp. 138-149.

Koutsouris, G., Norwich, B., Fujita, T., Ralph, T., Adlam, A. and Milton, F. (2017), "Piloting a dispersed and inter-professional Lesson Study using technology to link team members at a distance", Technology, Pedagogy and Education, Vol. 26 No. 5, pp. 587-599.

Lander, B. (2015), "Lesson study at the foreign language university level in Japan: blended learning, raising awareness of technology in the classroom", International Journal for Lesson and Learning Studies, Vol. 4 No. 4, pp. 362-382.

Lewis, C.C., Perry, R.R. and Hurd, J. (2009), "Improving mathematics instruction through lesson study: a theoretical model and North American case", Journal of Mathematics Teacher Education, Vol. 12 No. 4, pp. 285-304.

Lewis, C.C., Perry, R.R. and Murata, A. (2006), "How should research contribute to instructional improvement? The case of lesson study", Educational Researcher, Vol. 35 No. 3, pp. 3-14.

Major, L. and Watson, S. (2018), "Using video to support in-service teacher professional development: the state of the field, limitations and possibilities", Technology, Pedagogy and Education, Vol. 27 No. 1 , pp. 49-68.

Miles, M.B. and Huberman, A.M. (1994), Qualitative Data Analysis, Sage, Thousand Oaks.

Murooka, K. (2007), Current Status of Lesson Study in High Schools, Japanese Lesson Study in Mathematics: Its Impact, Diversity and Potential for Educational Improvement, World Scientific Publishing, Singapore, pp. 136-139.

Nami, F., Marandi, S.S. and Sotoudehnama, E. (2016), "Call teacher professional growth through lesson study practice: an investigation into EFL teachers' perceptions", Computer Assisted Language Learning, Vol. 29 No. 4, pp. 658-682.

Nickerson, S.D., Fredenberg, M. and Druken, B.K. (2014), "Hybrid lesson study: extending lesson study on-line", International Journal for Lesson and Learning Studies, Vol. 3 No. 2, pp. 152-169.

Pierce, R., Stacey, K., Wander, R. and Ball, L. (2011), "The design of lessons using mathematics analysis software to support multiple representations in secondary school mathematics", Technology, Pedagogy and Education, Vol. 20 No. 1, pp. 95-112.

Sharma, S.A. and Pang, S. (2015), "Creating new opportunities for lesson study in an online reading clinic", Literacy Research: Theory, Method, and Practice, Vol. 64 No. 1, pp. 415-428.

Skultety, L., Gonzalez, G. and Vargas, G. (2017), "Using technology to support teachers' lesson adaptations during lesson study”, Journal of Technology and Teacher Education, Vol. 25 No. 2, pp. 185-213.

Soto, M., Gupta, D., Dick, L. and Appelgate, M. (2019), "Bridging distances: professional development for higher education faculty through technology-facilitated lesson study", Journal of University Teaching and Learning Practice, Vol. 16 No. 3, pp. 1-17. 
Stokes, L.R.E., Suh, J.M. and Curby, T.W. (2020), "Examining the nature of teacher support during different iterations and modalities of lesson study implementation”, Professional Development in Education, Vol. 46 No. 1, pp. 97-111.

Supovitz, J.A. (2002), "Developing communities of instructional practice", Teachers College Record, Vol. 104 No. 8, pp. 1591-1626.

Timperley, H., Wilson, A., Barrar, H. and Fung, I. (2008), Teacher Professional Learning and Development: Best Evidence Synthesis Iteration, Ministry of Education, Wellington.

Turner, J.C., Christensen, A., Kackar-Cam, H.Z., Fulmer, S.M. and Trucano, M. (2018), "The development of professional learning communities and their teacher leaders: an activity systems analysis", Journal of the Learning Sciences, Vol. 27 No. 1, pp. 49-88.

Vermunt, J.D., Vrikki, M., van Halem, N., Warwick, P. and Mercer, N. (2019), "The impact of Lesson Study professional development on the quality of teacher learning", Teaching and Teacher Education, Vol. 81, pp. 61-73.

Vescio, V., Ross, D. and Adams, A. (2008), "A review of research on the impact of professional learning communities on teaching practice and student learning", Teaching and Teacher Education, Vol. 24 No. 1, pp. 80-91.

Wang, A., Yu, S., Wang, M. and Chen, L. (2019), "Effects of a visualization-based group awareness tool on in-service teachers' interaction behaviors and performance in a lesson study", Interactive Learning Environments, Vol. 27 Nos 5-6, pp. 670-684.

Webster, J. and Watson, R.T. (2002), "Analyzing the past to prepare for the future: writing a literature review”, MIS Quarterly, Vol. 26 No. 2, pp. xiii-xxiii.

\section{Corresponding author}

Stefan Hrastinski can be contacted at: stefanhr@kth.se
Digital teacher professional development

For instructions on how to order reprints of this article, please visit our website:

www.emeraldgrouppublishing.com/licensing/reprints.htm

Or contact us for further details: permissions@emeraldinsight.com 